\title{
Article \\ Chronic Pain and Associated Factors Related to Depression among Older Patients in Hanoi, Vietnam
}

\author{
Anh Trung Nguyen ${ }^{1,2, *(\mathbb{D})}$, Trang Huyen Thi Nguyen ${ }^{3,4}$, Thu Thi Hoai Nguyen ${ }^{1,2} \mathbb{D}$, Huong Thi Thu Nguyen ${ }^{1,2} \mathbb{D}$, \\ Thanh Xuan Nguyen 1,2 (D), Tam Ngoc Nguyen 1,2, Anh Lan Nguyen 1,2, Linh Gia Vu 3,4 ${ }^{10}$, Hoa Thi Do ${ }^{5}$, \\ Linh Phuong Doan ${ }^{5}$, Giang Thu Vu ${ }^{6}$, Huong Thi Thanh Nguyen ${ }^{7,8}$, Thang Pham ${ }^{1,2}$ \\ and Huyen Thi Thanh $\mathrm{Vu}^{1,2}$ (D)
}

Citation: Nguyen, A.T.; Nguyen, T.H.T.; Nguyen, T.T.H.; Nguyen, H.T.T.; Nguyen, T.X.; Nguyen, T.N.; Nguyen, A.L.; Vu, L.G.; Do, H.T.; Doan, L.P.; et al. Chronic Pain and Associated Factors Related to Depression among Older Patients in Hanoi, Vietnam. Int. J. Environ. Res. Public Health 2021, 18, 9192. https:// doi.org/10.3390/ijerph18179192

Academic Editor: Paul B. Tchounwou

Received: 22 June 2021

Accepted: 26 August 2021

Published: 31 August 2021

Publisher's Note: MDPI stays neutral with regard to jurisdictional claims in published maps and institutional affiliations.

Copyright: (c) 2021 by the authors Licensee MDPI, Basel, Switzerland. This article is an open access article distributed under the terms and conditions of the Creative Commons Attribution (CC BY) license (https:// creativecommons.org/licenses/by/ $4.0 /)$
1 Department of Geriatrics, Hanoi Medical University, Hanoi 100000, Vietnam; nththu.bvlk@gmail.com (T.T.H.N.); thuhuonglk@hmu.edu.vn (H.T.T.N.); xuanthanh1901vlk@gmail.com (T.X.N.); ngoctamyhn@gmail.com (T.N.N.); nguyenlananh.bvlk@gmail.com (A.L.N.); phamthang@hmu.edu.vn (T.P.); vuthanhhuyen11@hmu.edu.vn (H.T.T.V.)

2 Scientific Research Department, National Geriatric Hospital, Hanoi 100000, Vietnam

3 Institute for Global Health Innovations, Duy Tan University, Da Nang 550000, Vietnam; nguyenthuyentrang46@duytan.edu.vn (T.H.T.N.); vugialinh@duytan.edu.vn (L.G.V.)

4 Faculty of Medicine, Duy Tan University, Da Nang 550000, Vietnam

5 Institute of Health Economics and Technology, Hanoi 100000, Vietnam; dothihoa.iheat@gmail.com (H.T.D.); dplinh.iheat@gmail.com (L.P.D.)

6 Center of Excellence in Evidence-Based Medicine, Nguyen Tat Thanh University, Ho Chi Minh City 700000, Vietnam; giang.coentt@gmail.com

7 Dinh Tien Hoang Institute of Medicine, Hanoi 100000, Vietnam; huong.nguyen@dthim.org.vn

8 Physiology Department, Hanoi Medical University, Hanoi 100000, Vietnam

* Correspondence: trunganhvlk@gmail.com; Tel.: +84-090-348-0774

Abstract: The interaction of chronic pain and depression among older people has been studied for many years. This study aimed to investigate the frequency of chronic pain and depression among older patients and correlated factors. A cross-sectional study was conducted in 921 older patients at the National Geriatric Hospital from November 2019 to March 2020. We used the Charlson Comorbidity Index (CCI) to assess the comorbid condition, a numerical rating scale (NRS) to examine pain severity, and Geriatric Depression Scale-15 items (GDS-15) to measure depression among participants. A chi-square test and Tobit regression were used to analyze the relationships. A total of 921 older patients participated in the study. The proportion of depression accounted for $55.8 \%$. The mean Charlson score and number of diseases were 1.2 and 4.7, respectively. A positive correlation was found between comorbidity and chronic pain and depression. Moreover, socio-demographic variables such as occupation, education, and income were associated with pain and depressive symptoms. This study highlights the issue of mental health in older people with chronic pain. The results indicate the necessity of frequent depression screening, pain management, and social activity programs for older people to enhance their health.

Keywords: pain; older people; depression; chronic pain; Vietnam

\section{Introduction}

The Vietnamese population is growing old rapidly. The proportion of older people accounted for $8.7 \%$ of the total population in 2009 , which increased to $11.8 \%$ in 2019 [1]. This rapid transition might become a challenge for the healthcare system in order to ensure the health of the older population and improve health-related quality of life, including physical and mental health. Within those issues, chronic pain and depression are common physical and mental health problems in older people, which need proper prevention programs.

Older people with chronic pain also have a higher chance of functional disability compared to those younger [2]. Thus, these conditions have significant health and economic 
costs in some countries, where they have spent nearly $90 \%$ of the total health care cost for older adults [3]. Many studies have shown that mental health problems, such as anxiety, depression, and anger, are typically related to chronic pain [4]. Thus, the mental health problem in older people receives inadequate support from the government [5].

Mental health among older people also raises concerns from health care experts. Previous studies have shown that the prevalence of depression increases considerably among those who have chronic physical illnesses, including chronic pain [6-8]. Additionally, the percentage of older people in distress - physically, psychologically, or both—were high, accounting for $66 \%$ [9]. Many related factors might affect depression conditions, such as level of activity and demographic characteristics including age, income, gender, or behavior [10]. A previous study mentioned that nearly $70 \%$ of older people were at risk of mental health from mild to severe levels [11]. Depression in people with chronic pain frequently goes undiagnosed and untreated $[6,11]$. This may be due to the misunderstanding of depression among older people. Many people consider that depression is a part of the aging process [6]. On the other hand, depression does not have specific markers and objectives for diagnosis; thus, chronic pain and depression should be explored in research.

There have been few studies that have investigated depression and the associated factors related to depression conditions among older people in Vietnam. Therefore, this study aimed to describe the current situation of chronic pain and depression among older patients and the relationship between comorbidities, daily activities, chronic pain, and depression among this population.

\section{Materials and Methods}

\subsection{Study Design}

We conducted a cross-sectional study at the National Geriatric Hospital in Hanoi, Vietnam, from November 2019 to March 2020. We included the patients aged 60 years old and over with chronic pain at the National Geriatric Hospital. Eligible participants were invited to the private room and were introduced to this research. Registered nurses and nursing students provided information that made them fully understand the objectives, benefits, and shortcoming of the study. Those unable to communicate or who refused to participate in the interview during the recruitment process were excluded. There were a total of 921 participants in this study.

\subsection{Measure and Instruments}

\subsubsection{Socio-Economic Characteristics}

Gender, age, educational level, occupation, marital status, living status, living area, health insurance, and monthly individual income were compiled from self-reports. We also asked participants about their behaviors related to smoking and alcohol consumption. Smoking status was characterized by current smoker, former smoker, and non-smoker. Alcohol use was self-reported and classified as drinking alcohol and no alcohol.

\subsubsection{Comorbidity}

To examine the comorbidity of older patients, we used the Charlson Comorbidity Index (CCI), which categorized the comorbidity of patients from the hospital's data [12]. To measure the participant's comorbidity, we asked them to report their current pathological as well as acute health status, including myocardial infarction, congestive heart failure, peripheral vascular disease, dementia, chronic lung disease, cerebrovascular disease, and peptic ulcer.

\subsubsection{Pain Characteristics}

Chronic pain has been defined as pain that persists or re-occurs, lasting longer than 3 months [13]. 
To assess pain intensity, we used a numerical rating scale (NRS), which consists of 10 points from 0 (no pain) to 10 (worst possible pain) [14]. Patients were asked to choose a score from 0 to 10 to describe their pain intensity $[15,16]$.

Pain location (head-face-neck, shoulder-arm-elbow-hand, stomach-abdomen, backhip, knee-foot-leg, or other), number location of pain and satisfaction level with current pain medications (very unsatisfied, partly unsatisfied, satisfied, partly satisfied, and very satisfied) were included.

\subsubsection{Physical Activity}

To assess physical activity, we used the International Physical Activity Questionnaire (IPAQ), which included moderate and vigorous activity and walking in the past 7 days. Physical activity levels were categorized into low, moderate, and high levels based on the total score [17].

\subsubsection{Depression}

The 15-item Geriatric Depression Scale, Vietnamese version, was used to screen the depression condition in the older patients. The total scores range from 0 to 15 , in which scores of $0-5$ are considered normal and $6-15$ indicate having depressive symptom $[5,18]$.

\subsection{Statistical Analysis}

We described qualitative variables, socio-demographic, and the geriatric depression score among samples by using mean, standard deviation, number, and percentage. Statistically significant data were indicated at the $95 \%$ confidence level $(p<0.05)$. Comparisons between participants with depressive symptom and non-depressive symptom were assessed by using Chi-squared test for categorical variables and Student's t-tests for continuous variables. Tobit regression was used to examine factors associated with depression condition and pain intensity; the coefficient and 95\% CI (confident intervals) were also calculated. Stepwise with $p$-values $\leq 0.2$ for the Wald test was used to include variables in the model. The STATA software version 14.0 (Stata Corp. L.P., College Station, TX, USA) was adopted to perform all statistical analyses.

\section{Results}

Among 921 older patients, the mean age was 72.6 years $(\mathrm{SD}=9.2)$. The prevalence of older patients with depressive symptoms was $56.5 \%$. The mean age of older patients with depressive symptoms was 73.5 (9.5) years; two thirds were female, and $84.9 \%$ lived with their family. The proportion of people with health insurance was $95.1 \%$, and approximately two thirds had a monthly income of $\leq 3,000,000 \mathrm{VND}$ (approximately 129.47 USD) (Table 1).

Table 1. Demographic characteristics of respondents by depressive symptoms.

\begin{tabular}{|c|c|c|c|c|c|c|c|}
\hline & \multicolumn{2}{|c|}{$\begin{array}{c}\text { Depressive Symptoms } \\
520(56.5 \%)\end{array}$} & \multicolumn{2}{|c|}{$\begin{array}{c}\text { Non-Depressive Symptoms } \\
401(43.5 \%)\end{array}$} & \multicolumn{2}{|l|}{ All } & \multirow[t]{2}{*}{$p$-Value } \\
\hline & $\mathbf{n}$ & $\%$ & $\mathbf{n}$ & $\%$ & $\mathbf{n}$ & $\%$ & \\
\hline \multicolumn{8}{|l|}{ Gender } \\
\hline Male & 173 & 33.3 & 134 & 33.4 & 307 & 33.3 & 0.96 \\
\hline Female & 347 & 66.7 & 267 & 66.6 & 614 & 66.7 & \\
\hline \multicolumn{8}{|l|}{ Age } \\
\hline$\leq 70$ years old & 226 & 43.5 & 197 & 49.1 & 423 & 45.9 & 0.09 \\
\hline$>70$ years old & 294 & 56.5 & 204 & 50.9 & 498 & 54.1 & \\
\hline \multicolumn{8}{|l|}{ Occupation } \\
\hline Retired & 437 & 84.0 & 325 & 81.0 & 762 & 82.7 & 0.23 \\
\hline Working & 83 & 16.0 & 76 & 19.0 & 159 & 17.3 & \\
\hline \multicolumn{8}{|c|}{ Marital status (missing 5) } \\
\hline Single & 192 & 37.3 & 98 & 24.6 & 290 & 31.7 & $<0.01$ \\
\hline Married & 323 & 62.7 & 301 & 75.4 & 624 & 68.3 & \\
\hline \multicolumn{8}{|l|}{ Living status } \\
\hline Living with family & 425 & 81.7 & 357 & 89.0 & 782 & 84.9 & $<0.01$ \\
\hline Alone & 95 & 18.3 & 44 & 11.0 & 139 & 15.1 & \\
\hline
\end{tabular}


Table 1. Cont.

\begin{tabular}{|c|c|c|c|c|c|c|c|}
\hline & \multicolumn{2}{|c|}{$\begin{array}{c}\text { Depressive Symptoms } \\
520(56.5 \%)\end{array}$} & \multicolumn{2}{|c|}{$\begin{array}{c}\text { Non-Depressive Symptoms } \\
401(43.5 \%)\end{array}$} & \multicolumn{2}{|l|}{ All } & \multirow[t]{2}{*}{$p$-Value } \\
\hline & n & $\%$ & $\mathbf{n}$ & $\%$ & $\mathbf{n}$ & $\%$ & \\
\hline \multicolumn{8}{|c|}{ Self-monthly income (missing 3) } \\
\hline$\leq 3,000,000 \mathrm{VND}$ & 355 & 68.7 & 245 & 61.3 & 600 & 65.4 & 0.02 \\
\hline$>3,000,000 \mathrm{VND}$ & 162 & 31.3 & 155 & 38.8 & 317 & 34.6 & \\
\hline \multicolumn{8}{|l|}{ Health insurance } \\
\hline No & 494 & 95.0 & 382 & 95.3 & 876 & 95.1 & 0.86 \\
\hline Yes & 26 & 5.0 & 19 & 4.7 & 45 & 4.9 & \\
\hline \multicolumn{8}{|l|}{ Living area } \\
\hline Urban & 291 & 56.0 & 221 & 55.1 & 512 & 55.6 & 0.80 \\
\hline Rural & 229 & 44.0 & 180 & 44.9 & 409 & 44.4 & \\
\hline \multicolumn{8}{|c|}{ Educational level (missing 1) } \\
\hline$<$ High school & 125 & 24.1 & 86 & 21.4 & 211 & 22.9 & 0.15 \\
\hline High school & 137 & 26.4 & 115 & 28.7 & 252 & 27.4 & \\
\hline$>$ High school & 166 & 32.0 & 147 & 36.7 & 313 & 34.0 & \\
\hline \multirow[t]{2}{*}{ Others } & 91 & 17.5 & 53 & 13.2 & 144 & 15.7 & \\
\hline & Mean & SD & Mean & SD & Mean & SD & $p$-value \\
\hline Age & 73.5 & 9.5 & 71.4 & 8.6 & 72.6 & 9.2 & $<0.01$ \\
\hline
\end{tabular}

The pain characteristics of participants are displayed in Table 2. The proportion of pain in head-face-neck was highest in the group with depressive symptoms. Statically significant differences in depressive symptoms were found for pain located in the head-face-neck and knee-foot-leg areas, using pain medication and Charlson score. The proportion of patients using pain medication in the depressive symptom group was $56.9 \%$, higher than those without depressive symptom (Table 2).

Table 2. Pain characteristics in participants $(n=921)$.

\begin{tabular}{|c|c|c|c|c|c|c|c|}
\hline & \multicolumn{2}{|c|}{$\begin{array}{c}\text { Depressive Symptoms } \\
520(56.5 \%)\end{array}$} & \multicolumn{2}{|c|}{$\begin{array}{c}\text { Non-Depressive Symptoms } \\
401(43.5 \%)\end{array}$} & \multicolumn{2}{|c|}{ Total } & \multirow[t]{2}{*}{$p$-Value } \\
\hline & n & $\%$ & $\mathbf{n}$ & $\%$ & $\mathbf{n}$ & $\%$ & \\
\hline \multicolumn{8}{|l|}{ Pain location } \\
\hline Head-Face-Neck & 227 & 43.7 & 101 & 25.2 & 328 & 35.6 & $<0.01$ \\
\hline Shoulder-Arm-Elbow-Hand & 109 & 21.0 & 86 & 21.4 & 195 & 21.2 & 0.86 \\
\hline Stomach-Abdomen & 61 & 11.7 & 55 & 13.7 & 116 & 12.6 & 0.37 \\
\hline Back-Hip & 102 & 19.6 & 81 & 20.2 & 183 & 19.9 & 0.83 \\
\hline Knee-Foot-Leg & 158 & 30.4 & 161 & 40.1 & 319 & 34.6 & $<0.01$ \\
\hline Other & 135 & 26.0 & 71 & 17.7 & 206 & 22.4 & $<0.01$ \\
\hline \multicolumn{8}{|l|}{ Number location of pain } \\
\hline 0 & 58 & 11.2 & 47 & 11.7 & 105 & 11.4 & 0.88 \\
\hline 1 & 308 & 59.2 & 241 & 60.1 & 549 & 59.6 & \\
\hline$\geq 2$ & 154 & 29.66 & 113 & 28.2 & 267 & 29.0 & \\
\hline \multicolumn{8}{|c|}{ Satisfaction level with current pain medications } \\
\hline Very satisfied & 5 & 1.8 & 2 & 1.2 & 1.59 & 1.6 & 0.1 \\
\hline Partly satisfied & 20 & 7.2 & 20 & 12.2 & 40 & 9.1 & \\
\hline Satisfied & 201 & 72.6 & 124 & 75.6 & 325 & 73.7 & \\
\hline Partly unsatisfied & 46 & 16.6 & 17 & 10.4 & 63 & 14.3 & \\
\hline \multirow[t]{2}{*}{ Very unsatisfied } & 5 & 1.8 & 1 & 0.6 & 6 & 1.4 & \\
\hline & Mean & SD & Mean & $\mathrm{SD}$ & Mean & $\mathrm{SD}$ & $p$-value \\
\hline Charlson score & 1.6 & 1.4 & 1.3 & 1.5 & 1.5 & 1.5 & $<0.01$ \\
\hline NRS score & 4.6 & 1.8 & 4.5 & 1.5 & 4.6 & 1.7 & 0.66 \\
\hline
\end{tabular}

Table 3 presents the health-related behavior among older patients. Of the older patients in the depressive symptom group, $25.3 \%$ reported lifetime smoking, and $6.9 \%$ of those were current smokers. There were $119(26.9 \%)$ patients with a high physical activity level and $213(48.2 \%)$ patients with a moderate level, defined using the IPAQ questionnaire. The relationships between depressive symptoms and regular exercise and physical activity were statistically significant. 
Table 3. Health-related behavior among older people.

\begin{tabular}{|c|c|c|c|c|c|c|c|}
\hline \multirow{2}{*}{ Characteristics } & \multicolumn{2}{|c|}{ Depressive Symptoms } & \multicolumn{2}{|c|}{ Non-Depressive Symptoms } & \multicolumn{2}{|c|}{ Total } & \multirow{2}{*}{$p$-Value } \\
\hline & $\mathbf{n}$ & $\%$ & $\mathbf{n}$ & $\%$ & $\mathbf{n}$ & $\%$ & \\
\hline Current smoker & 26 & 6.9 & 16 & 4.9 & 42 & 6.0 & 0.27 \\
\hline Former smoker & 92 & 25.3 & 69 & 21.7 & 161 & 23.6 & 0.26 \\
\hline Drinking alcohol & 61 & 76.3 & 39 & 75.0 & 100 & 75.8 & 0.87 \\
\hline Regular exercise & 153 & 29.9 & 166 & 41.9 & 319 & 35.2 & $<0.01$ \\
\hline \multicolumn{8}{|c|}{ Physical Activity (IPAQ) } \\
\hline Low & 110 & 24.9 & 35 & 9.8 & 145 & 18.2 & $<0.01$ \\
\hline Moderate & 213 & 48.2 & 198 & 55.6 & 411 & 51.5 & \\
\hline High & 119 & 26.9 & 123 & 34.6 & 242 & 30.3 & \\
\hline
\end{tabular}

Table 4 presents odds ratios (ORs) and 95\% CI from the multiple logistic regression analysis of relationships between participants with depressive symptoms and related factors and a Tobit regression analysis of relationships between the numeric rating scale of pain and related factors. There was a statistically significant association between monthly income, pain location in head-face-neck and shoulder-arm-elbow-hand, satisfaction level with current pain medications, and numeric rating scale in pain and depressive symptoms.

Table 4. Factors associated with depression among the participants.

\begin{tabular}{|c|c|c|c|c|}
\hline & \multicolumn{2}{|c|}{ NRS } & \multicolumn{2}{|c|}{ Depressive Symptoms } \\
\hline & Coef & $95 \%$ CI & Coef & $95 \% \mathrm{CI}$ \\
\hline \multicolumn{5}{|l|}{ Socio-economic characteristic } \\
\hline Gender $($ Male $=$ ref $)$ & $-0.32 *$ & $(-0.64-0.01)$ & & \\
\hline \multicolumn{5}{|l|}{ Occupation (retired = ref) } \\
\hline Working & $0.40 *$ & $(-0.06-0.86)$ & & \\
\hline \multicolumn{5}{|c|}{ Monthly income $(\leq 3,000,000 \mathrm{VND}=$ ref $)$} \\
\hline$>3,000,000 \mathrm{VND}$ & & & $-0.57 * *$ & $(-1.12--0.03)$ \\
\hline \multicolumn{5}{|l|}{ Age $(\leq 70$ years old $=$ ref $)$} \\
\hline$>70$ years old & $0.36 * *$ & $(0.01-0.70)$ & & \\
\hline \multicolumn{5}{|l|}{ Physical activity } \\
\hline \multicolumn{5}{|l|}{ IPAQ (Low = ref) } \\
\hline Moderate & $-0.46^{* *}$ & $(-0.83--0.09)$ & & \\
\hline High & $-1.87^{* * *}$ & $(-2.36--1.38)$ & & \\
\hline \multicolumn{5}{|l|}{ Pain and Comorbid } \\
\hline Charlson comorbidity & $0.15^{* * *}$ & $(0.05-0.26)$ & & \\
\hline \multicolumn{5}{|l|}{ Pain location $(\mathrm{No}=$ ref $)$} \\
\hline Head-Face-Neck & & & 0.83 & $(0.29-1.37)$ \\
\hline Shoulder-Arm-Elbow-Hand & & & 0.66 & $(0.03-1.29)$ \\
\hline \multicolumn{5}{|c|}{ Satisfaction level with current pain medications (Very satisfied = ref) } \\
\hline Partly satisfied & 0.42 & $(-0.08-0.92)$ & $-1.76^{* * *}$ & $(-2.77--0.74)$ \\
\hline Partly unsatisfied & & & $-0.68 *$ & $(-1.37-0.01)$ \\
\hline NRS & & & 0.23 & $(0.08-0.38)$ \\
\hline
\end{tabular}




\section{Discussion}

Our study highlights a high proportion of patients with depression among study samples, at $56.5 \%$. Otherwise, the most common pain locations of the participants were head-face-neck and knee-foot-leg. Participants with moderate and high physical activity levels had better mental health conditions. These findings suggested the improvement of primary care for older people at a community level.

It is clear that older people become more sensitive to chronic illnesses, including chronic pain, while also being at higher risk of falling, frailty, and difficulty performing daily activities [2]. In this analyzed sample, the prevalence of depressive symptoms in women was higher than in men; this result is in line with a study in the United Kingdom, which also showed that women were more likely to indicate depressive symptoms than were men [19]. Undoubtedly, chronic pain is one of the obstacles to daily life in the elderly $[2,20,21]$. In the health context of Vietnam, there is a lack of medical facilities at the community level, and rehabilitation for older adults has not focused appropriately. These results also indicate that the early detection of depressive symptoms in patients with chronic pain is a great and important requirement for comprehensive geriatric assessment in hospitals. Age significantly interacts with pain severity, especially people over 70 years old. This is consistent with a study from China [22]. Therefore, pain management should be modified and designed for different ages and genders.

In addition to the pain issues, our research results also showed a correlation between comorbidity and depression in older patients. The results indicated that approximately $60 \%$ of the participants had a depressive symptom. This number was higher than a study conducted in a rural area in Vietnam, with $26.4 \%$ at risk for depression [5]. It is explained that older patients with chronic pain tend to develop depressive symptoms more often than older people in rural areas with non-chronic pain. The proportion of depressive symptoms in our sample is similar to that in the study from Lauren $\mathrm{R}$ [22]. Considering additional probably related factors of depression among the elderly, we found some positive associated factors mentioned above, such as pain location $[19,21]$ and comorbidity [9]. Multiple pain sites and a history of depression are factors that predict low outcomes. To tackle this problem, public health programs need to be more specific, in particular to support counseling and relieve depression in older people. Health workers need to be trained in health counseling, especially mental health. On the other hand, a lower monthly income was found to be associated with the likelihood of having a mental health problem, which is somewhat in line with the study of Mojtabai R [23,24]. It can be assumed that older people who had a monthly income might not have an economic burden or can afford their daily needs. In contrast, living in a rural area or earning less money can be an obstacle for older people in daily life, especially when they live alone [5]. Thus, it is important to establish chronic pain management programs for poor people in rural and mountainous areas.

As in our hypothesis, physical activity plays an essential role in the relationship between chronic pain and depression. In the current study, after adjusting for possible confounding factors, the elderly who had moderate and high physical daily activity were less likely to suffer a high intensity of pain. Moderate and high physical activity levels were associated with non-depressive symptoms in univariate analysis but were not statistically associated in the Tobit regression model. However, the result showed that moderate and high physical activity levels tend to decrease the pain severity. This result was similar with the finding in China [22]. It can be explained that doing physical activities might help people to strengthen the stretch of their low back, head-neck location, or muscles. Moreover, the effectiveness of physical therapy in chronic pain management was investigated [25,26]. Additionally, when older people doing physical activities enjoy doing exercise, riding a bike, playing any kind of sport, they would prefer to do it in a group of people, which may help them to open their social network and reduce the chance of being alone and at risk of depression. Therefore, those activities might decrease the symptom of depression [11,27,28]. It is suggested that developing occupational therapy and physical therapy training in 
Vietnam is critical. On the other hand, engaging social networks should be indicated in hospital, because, in Vietnam, social workers are still lacking in the healthcare system. There are several implications in our study. First, our results reported the current prevalence risk for depression among older people with chronic pain, which should not be misjudged or considered a part of aging. It can be seen from a clinical perspective that we should not underestimate physical examination. Physical activities in older people not only correlate with pain but are also associated with depression, including people with low physical pain. Therefore, we need to work towards homecare service and develop policies to promote activities for older adults of both rural and urban areas, which might help older adults receive healthcare at home. Our research has some limitations. The cross-sectional study might mean it is difficult to conclude the causal relationship between socio-demographic characteristics and other variables and outcomes, which demand further study.

\section{Conclusions}

This study highlights the issue of mental health in older people with chronic pain. The results indicated the necessity of frequent depression screening, pain management, physical activity programs, and social activity programs for older people to enhance their health. Future longitudinal studies should explore the relationship between socio-demographic characteristic and physical activity with chronic pain and pain-related outcomes.

Author Contributions: Conceptualization, A.T.N., H.T.T.V., T.X.N., T.T.H.N., H.T.T.N. (Huong Thi Thanh Nguyen), and T.N.N.; methodology, T.X.N., A.T.N., H.T.T.V., G.T.V., and T.H.T.N.; software, T.T.H.N., H.T.T.N. (Huong Thi Thu Nguyen), and H.T.D.; validation, A.T.N., H.T.T.V., T.X.N., T.T.H.N., and T.N.N.; formal analysis, T.H.T.N., T.T.H.N., L.P.D., and H.T.T.V.; investigation, A.T.N. and H.T.T.V.; resources, A.T.N.; data curation, A.L.N., T.N.N., T.T.H.N., and T.X.N.; writingoriginal draft preparation, A.T.N., H.T.T.V., T.X.N., T.T.H.N., T.H.T.N., L.G.V., G.T.V., T.P., and H.T.T.N. (Huong Thi Thu Nguyen); writing-review and editing, A.T.N., H.T.T.V., T.X.N., T.T.H.N., T.H.T.N., L.G.V., G.T.V., T.P., A.L.N., H.T.D., H.T.T.N. (Huong Thi Thu Nguyen), L.P.D., H.T.T.N. (Huong Thi Thanh Nguyen), and T.N.N.; visualization, A.T.N. and H.T.T.V.; supervision, H.T.T.V.; project administration, T.T.H.N. All authors have read and agreed to the published version of the manuscript.

Funding: This research received no external funding.

Institutional Review Board Statement: The study protocol was approval by the Ethics Committee of National Geriatric Hospital with the number 635/IRB-NGH.

Informed Consent Statement: Written informed consent has been obtained from the patient(s) to publish this paper.

Data Availability Statement: The datasets of this study are available from the corresponding author on reasonable request.

Acknowledgments: We would like to express our deepest gratitude for the great support of the National Geriatric Hospital, Hanoi, Vietnam while we conducted our research and the support of Hanoi Medical University, Hanoi, Vietnam for partly funding our data collection.

Conflicts of Interest: The authors declare no conflict of interest.

\section{References}

1. Giang, L. The Aging Population in Viet Nam: Current Status, Prognosis, and Possible Policy Responses. UNFPA 2011. Available online: https:/ / vietnam.unfpa.org/en/publications/ageing-population-viet-nam-current-status-prognosis-and-possible-policyresponses. (accessed on 10 September 2020).

2. Fong, J.H. Disability incidence and functional decline among older adults with major chronic diseases. BMC Geriatr. 2019, 19, 1-9. [CrossRef]

3. Chi, M.-J.; Lee, C.-Y.; Wu, S.-C. The prevalence of chronic conditions and medical expenditures of the elderly by chronic condition indicator (CCI). Arch. Gerontol. Geriatr. 2011, 52, 284-289. [CrossRef]

4. Lee, H.J.; Nahm, F.S.; Yoon, I.Y.; Lee, P.B. Prevalence of unrecognized depression in patients with chronic pain without a history of psychiatric diseases. Korean J. Pain. 2018, 31, 116-124. [CrossRef] [PubMed] 
5. Vu, H.T.T.; Lin, V.; Pham, T.; Le Pham, T.; Nguyen, A.T.; Nguyen, H.T.; Nguyen, T.X.; Nguyen, T.N.; Nguyen, H.T.T.; Nguyen, T.T.H.; et al. Determining Risk for Depression among Older People Residing in Vietnamese Rural Settings. Int. J. Environ. Res. Public Health 2019, 16, 2654. [CrossRef] [PubMed]

6. Centers for Disease Control and Prevention. Depression is Not a Normal Part of Growing Older. In Healthy Brain Initiative. Available online: https://www.cdc.gov/aging/mentalhealth/depression.htm (accessed on 20 September 2020).

7. Sheng, J.; Liu, S.; Wang, Y.; Cui, R.; Zhang, X. The Link between Depression and Chronic Pain: Neural Mechanisms in the Brain. Neural Plast. 2017, 2017, 1-10. [CrossRef]

8. Holmes, A.; Christelis, N. Depression and chronic pain. Med. J. Aust. 2013, 199, S17-S20. [CrossRef] [PubMed]

9. Joshi, K.; Kumar, R.; Avasthi, A. Morbidity profile and its relationship with disability and psychological distress among elderly people in Northern India. Int. J. Epidemiol. 2003, 32, 978-987. [CrossRef] [PubMed]

10. Tanır, H.; Özmaden, M. The Importance of Physical Activity in the Protection of the Mental Health of Students of Faculty of Sport Sciences. J. Educ. Train. Stud. 2018, 6, 92-97. [CrossRef]

11. Dao, A.T.M.; Nguyen, V.T.; Nguyen, H.V.; Nguyen, L.T.K. Factors Associated with Depression among the Elderly Living in Urban Vietnam. BioMed Res. Int. 2018, 2018, 1-9. [CrossRef]

12. Hall, W.H.; Ramachandran, R.; Narayan, S.; Jani, A.B.; Vijayakumar, S. An electronic application for rapidly calculating Charlson comorbidity score. BMC Cancer 2004, 4, 94. [CrossRef]

13. Treede, R.-D.; Rief, W.; Barke, A.; Aziz, Q.; Bennett, M.I.; Benoliel, R.; Cohen, M.; Evers, S.; Finnerup, N.B.; First, M.B.; et al. A classification of chronic pain for ICD-11. Pain 2015, 156, 1003-1007. [CrossRef]

14. Haefeli, M.; Elfering, A. Pain assessment. Eur. Spine J. 2006, 15 (Suppl. 1), S17-S24. [CrossRef]

15. Closs, S.; Barr, B.; Briggs, M.; Cash, K.; Seers, K. A comparison of five pain assessment scales for nursing home residents with varying degrees of cognitive impairment. J. Pain Symptom Manag. 2004, 27, 196-205. [CrossRef] [PubMed]

16. Farrar, J.T.; Young, J.P.; Lamoreaux, L.; Werth, J.L.; Poole, M.R. Clinical importance of changes in chronic pain intensity measured on an 11-point numerical pain rating scale. Pain 2001, 94, 149-158. [CrossRef]

17. Tran, D.V.; Lee, A.; Au, T.B. Reliability and validity of the International physical activity Questionnaire-Short form for older adults in Vietnam. Health Promot. J. Aust. 2013, 24, 126-131. [CrossRef] [PubMed]

18. Vinkers, D.J.; Gussekloo, J.; Stek, M.L.; Westendorp, R.G.J.; Van Der Mast, R.C. The 15-item Geriatric Depression Scale(GDS-15) detects changes in depressive symptoms after a major negative life event. The Leiden 85-plus Study. Int. J. Geriatr. Psychiatry 2004, 19, 80-84. [CrossRef] [PubMed]

19. Lauren, R.; Matthew, H.; Hristina, P. Depression in patients with chronic pain attending a specialised pain treatment centre: Prevalence and impact on health care costs. Pain 2017, 157, 1472-1479.

20. Gijsen, R.; Hoeymans, N.; Schellevis, F.G.; Ruwaard, D.; Satariano, W.A.; Bos, G.A.V.D. Causes and consequences of comorbidity: A review. J. Clin. Epidemiol. 2001, 54, 661-674. [CrossRef]

21. Carrington, R.M.; Christopher, E.; Karl, P. Management of chronic pain in older adults. BMJ 2015, 350, h532.

22. Liu, X.; Xiao, S.; Zhou, L. Different predictors of pain severity across age and gender of a Chinese rural population: A crosssectional survey. BMJ Open 2018, 8, e020938. [CrossRef] [PubMed]

23. Mossey, J.M.; Gallagher, R.M.; Tirumalasetti, F. The Effects of Pain and Depression on Physical Functioning in Elderly Residents of a Continuing Care Retirement Community. Pain Med. 2000, 1, 340-350. [CrossRef]

24. Mojtabai, R.; Olfson, M. Major depression in community-dwelling middle-aged and older adults: Prevalence and 2- and 4-year follow-up symptoms. Psychol. Med. 2004, 34, 623-634. [CrossRef] [PubMed]

25. Jitender, S.; Tracie, O.A.; Katherine, A.M. Relationship between household income and mental disorders-Findings from a population-based longitudinal study. JAMA 2011, 68, 419-427.

26. Roesch, R.; Ulrich, D.E. Physical Therapy Management in the Treatment of Chronic Pain. Phys. Ther. 1980, 60, 53-57. [CrossRef] [PubMed]

27. Louise, J.G.; Moore, R.A.; Clare, C. Physical activity and erxercise for chornic pain in adults: An overview of Cochrane Reviews. Cochrane Database Syst. Rev. 2017, 1, CD011279. [CrossRef]

28. Laura, F.L.; Kathleen, A.S. How does physical activity modulate pain. Pain 2017, 158, 369-370. 